\title{
Association of Dental Anxiety with Psychosocial Characteristics among Children Aged 7-13 Years
}

\author{
Mariana Gonzalez Cademartori ${ }^{1}\left[\right.$, Denise Paiva da Rosa ${ }^{1}\left[{ }^{(0,}\right.$, Letícia Coutinho Brancher ${ }^{1}$, Vanessa \\ Polina Pereira Costa1 ${ }^{1}$, Marília Leão Goettems ${ }^{1}$ (])
}

${ }^{1}$ Graduate Program in Dentistry, School of Dentistry, Federal University of Pelotas, Pelotas, RS, Brazil.

Author to whom correspondence should be addressed: Mariana Gonzalez Cademartori, Federal University of Pelotas, School of Dentistry, 457, Gonçalves Chaves Street, Pelotas, RS, Brazil. Phone: +55 53 98135-1584. E-mail: marianacademartori@gmail.com.

Academic Editors: Alessandro Leite Cavalcanti and Wilton Wilney Nascimento Padilha

Received: 11 April 2019 / Accepted: 10 December 2019 / Published: 17 January 2020

How to cite this article: Cademartori MG, Rosa DP, Brancher LC, Costa VPP, Goettems ML. Association of dental anxiety with psychosocial characteristics among children aged 7-13 years. Pesqui Bras Odontopediatria Clín Integr. 2020; 20:e4635. https://doi.org/10.1590/pboci.2020.028

\begin{abstract}
Objective: To identify psychosocial characteristics associated with dental anxiety in children aged 7-13 years in the dental setting. Material and Methods: This cross-sectional study was conducted with children aged 7-13 years attended at the Dentistry School of Pelotas, Brazil. Data collection was based on a questionnaire administered to mothers and children, and the behavior of children during dental treatment was evaluated using the Frankl' Scale. Data were analyzed using Chi-square and Fisher's exact tests in order to analyze the association between independent variables and dental anxiety. The effect of variables on the outcome was assessed by the Poisson regression model with robust variance (Prevalence Ratio; 95\% Confidence interval). Results: A total of 187 children were included. Dental anxiety prevalence was 40.11\%. After adjustments, younger children $(\mathrm{p}=0.046)$, only child $(\mathrm{p}=0.019)$, and children with negative previous dental experience $(\mathrm{p}=0.046)$ showed higher dental anxiety prevalence. Children with uncooperative behavior in previous $(\mathrm{p}=0.033)$ and current $(\mathrm{p} \leq 0.001)$ dental appointments showed higher dental anxiety prevalence. Conclusion: In this sample of children treated at a dentistry school, a report of dental anxiety was associated with age, birth order, previous dental experience and behavior in dental settings.
\end{abstract}

Keywords: Pediatric Dentistry; Child Behavior; Dental Anxiety. 


\section{Introduction}

Dental anxiety is conceptualized as a negative emotional state related to dental treatment and often unreasonably and excessively manifested by patients [1]. Dental anxiety has a prevalence of $10 \%$ among children and adolescents [1], decreasing with age [1,2]. Dental anxiety in children is predicted by several factors, including socioeconomic and demographic characteristics. Girls, younger age, poverty and low maternal educational level are associated with dental anxiety [1-3].

Dental anxiety represents one of the most undesirable problems that affect pediatric dentistry since anxious children tend to present uncooperative behavior during dental care [4,5]. Behavior problems can be a natural response to fear, especially when the child experiences new situations [6]. Dental anxiety in children has also been associated with poor oral health, such as active dental caries [3,7], dental pain [8], and poor oral health behaviors, such as toothbrushing less than twice a day and irregular dental attendance patterns $[7,8]$, negatively affecting their quality of life [7].

Psychosocial characteristics have been identified as other important factors associated with dental anxiety in children. Previous authors identified that dentally anxious children impact more on family life than those without dental anxiety [7]. In the same line, children whose parents are highly anxious had almost three times more likely to report high dental anxiety [9]. In addition to the family issue, the child's personal characteristics, such as emotionality and shyness temperaments [5], and social problems, have been associated with the presence of dental anxiety. On the other hand, children with pro-social behavior have significantly less anxiety when compared to those with social and emotional problems [6,10].

Since dental anxiety plays an important role in children's health and is one of the main causes of behavioral problems during dental treatment, the aim of this study was to identify psychosocial characteristics associated with dental anxiety in children aged 7-13 years in the dental setting.

\section{Material and Methods}

Study Design and Subjects

This cross-sectional study was conducted with children aged 7-13 years who attended at the Pediatric Dental Clinic, School of Dentistry, Federal University of Pelotas (UFPel) between July 2017 and July 2018. Children who look for the Pediatric Clinic are from free demand or referred from Basic Health Units in the city or other professionals. For inclusion in this study, children should be accompanied by parents and not have any physician-diagnosed mental and physical illness.

To assess dental anxiety prevalence, the estimated minimum sample size was calculated assuming the following parameters: dental fear/anxiety prevalence estimated at 10\% [1], a margin of error of $5 \%$ points, and confidence level of $95 \%$. To cover non-response, the sample was increased by $10 \%$, resulting in 153 children.

\section{Data Collection}

Data collection consisted of an interview with mothers and children, and child behavior was assessed during the dental appointment. The questionnaire was applied to mothers about demographic and socioeconomic information, and child's psychosocial characteristics. The interview with children was conducted away from mothers and after dental treatment. They were asked about dental fear.

Independent Variables 
Subjects were classified as children (7-9.9 years) or adolescents (10-13 years), according to the World Health Organization. Family structure was categorized as nuclear (when children lived with both parents) and non-nuclear. The number of siblings was categorized as "Only child" and "One or more siblings".

Information on previous negative dental experience was collected using the question: "Your child had some medical experience or with a health professional that you judges have been pretty unpleasant and caused distress in his/her child?" The possible answers were "Yes" or "No".

Variable first dental appointment was collected with the following question: "Has your child ever been to the dentist?" with answers: "No, this is the first time" and "Yes". The previous negative dental experience was investigated using the following question: "Your child had some experience with a dentist or in a dental appointment that you judges have been pretty unpleasant and caused distress in his/her child?”. The possible answers were "Yes" or "No".

History of previous uncooperative behavior in dental appointments was investigated using the following question "In previous dental appointments, did your child present behaviors that prevented the dental care or refused to receive it?" with two possible answers: "Yes" or "No".

Behavior during dental treatment was assessed using Frankl's Scale [11]. The Frankl's Scale rates the child's behavior in four categories according to specific criteria: Definitely Negative, Negative, Positive and Definitely Positive. Mean behavior ratings were obtained for each child, considering the three different moments. The overall score of the Frankl's Scale was considered. The overall score consists of the mean score obtained from the sum of individual ratings received from three different moments during the appointment: at the beginning (including separation from the mother), during the treatment procedure, and conclusion. For data analyses, scores were dichotomized into Cooperative behavior (positive) and Uncooperative behavior (negative). The presence of dental pain was investigated with the following question [12]: "Has your son/daughter had dental pain in the last 4 weeks?" The answers were "No" (absent) and "Yes" (present).

\section{Outcome Variable}

Outcome (dental anxiety) was collected using Dental Anxiety Questionnaire (DAQ) [13]: 'Are you afraid of going to the dentist?' with the following response options: 'No', 'Yes', 'Yes, a little', 'Yes, a lot'. DAQ was dichotomized into no (no category) and yes (yes; yes, a little; and yes, a lot of categories).

\section{Training and Calibration Process}

For the interview, three-hour theoretical training was conducted with interviewers and questions were discussed. The evaluation of a child's behavior was performed by two independent observers, Masters in Pediatric Dentistry. Observers were trained and calibrated for the application of the Frankl's Scale. Initially, two-hour theoretical training was conducted and criteria were discussed. The calibration process was performed at the Pediatric Dentistry Clinic of the School of Dentistry - UFPel, with 24 children in the same age group of this study, but not included in the final sample. Concordance was assessed by the Kappa coefficient and the inter-examiner agreement was tested against a 'gold standard' examiner. Inter-examiner Kappa values were 0.89 and 0.90 .

\section{Ethical Approval}

The study design was approved by the Ethics Research Committee from the Federal University of Pelotas (Protocol No. 29/2013). All mothers were invited to participate in this study and signed the informed 
consent form. All children were invited to participate and signed the assent form. To test the proposed methodology, a pilot study involving 12 children (aged 7-13 years) was carried out prior to data collection. These children were not included in the final sample.

\section{Statistical Analysis}

Absolute and relative frequencies were obtained by descriptive analysis. Chi-square and Fisher's exact tests were used to analyze the effect of independent variables on the outcome (dental fear). The association between the independent variables and the outcome was assessed by the Poisson regression model with robust variance (Prevalence Ratio=PR; CI 95\%; p $\leq 0.05$ ). A forward stepwise procedure was used to include or exclude explanatory variables in the model fitting. Variables with p-values $\leq 0.20$ in the crude analyses were included in the model fitting. Variables were removed from the model from the highest to the lowest until all variables showed p-values $\leq 0.20$. For the final model, variables were considered significant if p-value $\leq 0.05$ after adjustment. Analyses were carried out using Stata version 12.0 software (Stata Corporation, College Station, TX, USA).

\section{Results}

A total of 187 mother-child dyads participated of study (response rate $=100 \%$ ). No mother or child refused to participate. Most children were females (53.5\%), aged 7-10 years (74.3\%), had one or more siblings $(73.3 \%)$ and part of a nuclear family structure (63.6\%). Dental fear prevalence was $40.11 \%$.

In addition, most children did not have previous negative medical (83.4\%) or dental (75.6\%) experience, had already visited the dentist (96.2\%), reported no dental fear (77.5\%) and did not have dental pain in the last month $(62.6 \%)$. With respect to behavior in dental appointments, $85.6 \%$ of children had cooperative behavior in previous dental appointments and $89.3 \%$ had cooperative behavior in a current dental appointment.

The fact that the child had not to visit the dentist before $(\mathrm{p}=0.017)$, previous negative experience with the dentist $(\mathrm{p}=0.029)$, previous behaviors in dental appointment $(\mathrm{p}=0.009)$ and child behavior during the appointment $(\mathrm{p} \leq 0.001)$ were associated with child dental fear.

Table 1. Child dental anxiety according to demographic, socioeconomic, clinical children and maternal characteristics.

\begin{tabular}{|c|c|c|c|c|}
\hline \multirow{3}{*}{ Variables } & \multicolumn{4}{|c|}{ Child Dental Anxiety } \\
\hline & Total & No & Yes & p-value \\
\hline & $\mathrm{N}(\%)$ & $\mathrm{N}(\%)$ & $\mathrm{N}(\%)$ & \\
\hline Age (Years) & & & & 0.073 \\
\hline $7-10$ & $139(74.33)$ & $78(56.1)$ & $61(43.9)$ & \\
\hline $11-13$ & $48(25.67)$ & $34(70.8)$ & $14(29.2)$ & \\
\hline Sex & & & & 0.127 \\
\hline Male & $87(46.52)$ & $47(54.1)$ & $40(45.9)$ & \\
\hline Female & $100(53.48)$ & $65(65.0)$ & $35(35.0)$ & \\
\hline Family Structure & & & & 0.248 \\
\hline Nuclear & $119(63.64)$ & $75(63.1)$ & $44(36.9)$ & \\
\hline Non-nuclear & $68(36.36)$ & $37(54.4)$ & $31(45.6)$ & \\
\hline Number of Siblings & & & & 0.162 \\
\hline Only child & $50(26.74)$ & $34(68.0)$ & $16(32.0)$ & \\
\hline$\geq 1$ & $137(73.26)$ & $78(56.9)$ & $59(43.1)$ & \\
\hline Previous Negative Medical Experience & & & & $<0.001$ \\
\hline No & $156(83.42)$ & $93(59.6)$ & $63(40.4)$ & \\
\hline Yes & $31(16.58)$ & $19(61.3)$ & $12(38.7)$ & \\
\hline
\end{tabular}


First Dental Appointment

\begin{tabular}{|c|c|c|c|c|}
\hline First Dental Appointment & & & & $0.017 * *$ \\
\hline Yes & $7(3.74)$ & $1(14.3)$ & $6(85.7)$ & \\
\hline No & $180(96.26)$ & $111(61.7)$ & $69(38.3)$ & \\
\hline Previous Negative Experience with Dentist* & & & & 0.029 \\
\hline No & $136(75.56)$ & $90(66.2)$ & $46(33.8)$ & \\
\hline Yes & $44(24.44)$ & $21(47.7)$ & $23(52.3)$ & \\
\hline Previous Behaviors in Dental Appointments* & & & & 0.009 \\
\hline Cooperative behavior & $154(85.55)$ & $101(65.6)$ & $53(34.4)$ & \\
\hline Uncooperative behavior & $26(14.45)$ & $10(38.5)$ & $16(61.5)$ & \\
\hline Behavior in the Appointment & & & & $<0.001 * *$ \\
\hline Cooperative behavior & $167(89.30)$ & $107(64.1)$ & $60(35.9)$ & \\
\hline Uncooperative behavior & $20(10.70)$ & $5(25.0)$ & $15(75.0)$ & \\
\hline Dental Pain (in the last month) & & & & 0.226 \\
\hline No & $117(62.57)$ & $74(63.3)$ & $43(36.7)$ & \\
\hline Yes & $70(37.43)$ & $38(54.3)$ & $32(45.7)$ & \\
\hline
\end{tabular}

*It was considered only those children who visited the dentist, $\mathrm{n}=180$; **Exact Fisher Test.

In the crude analysis, first dental visit $(\mathrm{p} \leq 0.001)$, previous negative experience with dentist $(\mathrm{p}=0.021)$, previous negative behavior in dental appointments $(\mathrm{p}=0.002)$ and negative behavior during the dental appointment $(\mathrm{p} \leq 0.001)$ were associated with higher dental fear prevalence. After adjustments, younger children $(\mathrm{p}=0.046)$ who do not have siblings $(\mathrm{p}=0.019)$ and with previous negative dental experience $(\mathrm{p}=0.046)$ showed higher dental fear prevalence than other children. Children with uncooperative behavior in previous $(\mathrm{p}=0.033)$ and current $(\mathrm{p} \leq 0.001)$ dental appointments showed higher dental fear prevalence.

Table 2. Association between independent variables and child dental anxiety - Crude and adjusted analysis.

\begin{tabular}{|c|c|c|c|c|}
\hline \multirow[b]{2}{*}{ Variables } & \multicolumn{4}{|c|}{ Child Dental Anxiety } \\
\hline & $\begin{array}{c}\text { PR }(95 \% \text { CI }) \\
\text { Crude }\end{array}$ & p-value & $\begin{array}{c}\text { PR }(95 \% \text { CI }) \\
\text { Adjusted }\end{array}$ & p-value \\
\hline Age (Years) & & 0.096 & & 0.046 \\
\hline 7-10 (ref. 11-13) & $1.50(0.93-2.43)$ & & $1.61(1.01-2.58)$ & \\
\hline Sex & & 0.129 & & \\
\hline Female (ref. Male) & $0.76(0.54-1.08)$ & & ---- & \\
\hline Family Structure & & 0.242 & & \\
\hline Non-nuclear (ref. Nuclear) & $1.23(0.87-1.75)$ & & ---- & \\
\hline Number of Siblings & & 0.195 & & 0.019 \\
\hline$\geq 1$ (ref. Only child) & $1.34(0.86-2.11)$ & & $1.82(1.10-3.01)$ & \\
\hline Previous Negative Medical Experience & & 0.864 & & \\
\hline Yes (ref. No) & $0.96(0.59-1.55)$ & & ---- & \\
\hline First Dental Appointment & & $\leq 0.001$ & & \\
\hline No (ref. Yes) & $2.24(1.57-3.19)$ & & ---- & \\
\hline Previous Negative Experience With Dentist* & & 0.021 & & 0.046 \\
\hline Yes (ref. No) & $1.54(1.07-2.23)$ & & $1.47(1.01-2.14)$ & \\
\hline Previous Behaviors in Dental Appointments* & & 0.002 & & 0.033 \\
\hline Uncooperative behavior (ref. Cooperative behavior) & $1.78(1.22-2.62)$ & & $1.53(1.03-2.28)$ & \\
\hline Behavior in the Appointment & & $\leq 0.001$ & & $\leq 0.001$ \\
\hline Uncooperative behavior (ref. Cooperative behavior) & $2.09(1.51-2.89)$ & & $2.39(1.69-3.38)$ & \\
\hline Dental Pain (in the last month) & & 0.221 & & \\
\hline Yes (ref. No) & $1.24(0.87-1.76)$ & & --- & \\
\hline
\end{tabular}

$\mathrm{PR}=$ Prevalence Ratio; *It was considered only those children who visited the dentist, $\mathrm{n}=180$; **Variables with $\mathrm{p} \leq 0.200$ at crude analysis were included in the final model after the adjustment.

\section{Discussion}

According to our findings, younger age, only child, negative previous dental experience, and uncooperative behavior in previous and current dental appointments were associated with dental anxiety in children aged 7-13 years. 
Although the literature shows that girls [1,2] and younger children [1,2] are more anxious than boys or older children, the present study found no statistically significant differences related to gender. However, children aged 7-9.9 years reported significant higher dental anxiety than those aged 10-13 years. In fact, studies have shown that the dental fear/anxiety prevalence decreases with increasing age, discussing the maladaptive trait present during childhood, especially in earlier children, as the risk factor for that [1,2].

The family environment has been considered as another important factor associated with dental anxiety in children. Dentally anxious children are less likely of having poor oral health and poor oral health behaviors, such as not going to the dentist for regular dental examinations and to brush teeth twice a day [7]. The oral health of dentally anxious children impacts more on family life than children with no dental anxiety [7]. In the same line, only children have demonstrated being more anxious than the other children [14]. Only children are at the core center of attention and care and tend to be more vulnerable to stressful situations such as dental treatment [15].

Children with previous negative experiences had increased anxiety as a result of the idea of having the same type of unpleasant situation again [16]. In this study, children who had a negative experience with the dentist had higher dental anxiety prevalence compared with children who had no negative experience. Negative dental experiences are predictive of dental fear/anxiety, and are strongly associated with it than any type of dental procedure to be performed [16]. In addition, it seems that this feeling is associated with negative memories of events related to pain and dentist behaviors, facilitating the vivid reliving of negative episodes [17]. Thus, psychological strategies for the first visit with the aim of reducing dental fear are deeply necessary, especially with very young children.

Behavior in previous dental appointments may help predict child behavior and emotional reactions in the next dental appointment. In this study, a statistically significant association was found between child behavior during dental care and dental anxiety, in accordance with previous studies [7,17]. Children with uncooperative behavior during previous dental appointments and in current dental appointment had higher dental anxiety prevalence than those with cooperative behavior. Having beforehand information about the child allows the pediatric dentist to plan to spend more time and effort in teaching children to cope [17]. Therefore, the screening for child dental anxiety could enable the pediatric dentist prepares children to positive treatment experiences [17].

The limitation of this study is its cross-sectional design, which does not allow establishing cause and effect relationships. Moreover, the sample was composed of children attended in a public reference service. However, this study explored the psychosocial characteristics of children, which are still controversial issues, as gender, birth order and family structure. Further studies should be performed to know the history of dental fear and to design effective strategies in Pediatric Dentistry.

\section{Conclusion}

In this sample of children treated at a dentistry school, it was found that the child report of dental anxiety was associated with age, birth order, previous dental experience and behavior presented during dental treatment. Thus, these factors should be considered by the pediatric dentistry to identify children who tend to show higher dental anxiety, and to propose strategies to minimize this condition.

\section{Authors' Contributions}

MGC (D) 0000-0002-2433-8298 Conceptualization, Methodology, Investigation, Formal Analysis, Writing Original Draft Preparation, and Writing - Review and Editing. 
DPR (D) 0000-0003-1807-5775 Investigation, Writing-Original Draft Preparation.

LCB (D) 0000-0002-0692-762X Investigation, Writing - Original Draft Preparation.

VPPC (D) 0000-0003-0524-6870 Conceptualization, Methodology, Formal Analysis.

MLG (D) 0000-0002-6512-2602 Conceptualization, Methodology, Formal Analysis.

All authors declare that they contributed to critical review of intellectual content and approval of the final version to be published.

\section{Financial Support}

None.

\section{Conflict of Interest}

The authors declare no conflicts of interest.

\section{References}

[1] Cianetti S, Lombardo G, Lupatelli E, Pagano S, Abraha I, Montedori A, et al. Dental fear/anxiety among children and adolescents. A systematic review. Eur J Paediatr Dent 2017; 18(2):121-30. https://doi.org/10.23804/ejpd.2017.18.02.07

[2] Shim YS, Kim AH, Jeon EY, An SY. Dental fear \& anxiety and dental pain in children and adolescents; a systemic review. J Dent Anesth Pain Med 2015; 15(2):53-61. https://doi.org/10.17245/jdapm.2015.15.2.53

[3] Soares FC, Lima RA, Santos CF, de Barros MV, Colares V. Predictors of dental anxiety in Brazilian 5-7years old children. Compr Psychiatry 2016; 67:46-53. https://doi.org/10.1016/j.comppsych.2016.01.006

[4] Pezzini Soares J, Cardoso M, Bolan M. Demystifying behaviour and dental anxiety in schoolchildren during endodontic treatment for primary teeth-controlled clinical trial. Int J Paediatr Dent 2019; 29(3):249-56. https://doi.org/10.1111/ipd.12468

[5] Jain A, Suprabha BS, Shenoy R, Rao A. Association of temperament with dental anxiety and behaviour of the preschool child during the initial dental visit. Eur J Oral Sci 2019; 127(2):147-55. https://doi.org/10.1111/eos.12606

[6] Salem K, Kousha M, Anissian A, Shahabi A. Dental fear and concomitant factors in 3-6 year-old children. J Dent Res Dent Clin Dent Prosp 2012; 6(2):70-4. https://doi.org/10.5681/joddd.2012.015

[7] Coxon JD, Hosey MT, Newton JT. The oral health of dentally anxious five- and eight-year-olds: a secondary analysis of the 2013 Child Dental Health Survey. Br Dent J 2019; 226(7):503-7. https://doi.org/10.1038/s41415-019-0148-3

[8] Colares V, Franca C, Ferreira A, Amorim Filho HA, Oliveira MC. Dental anxiety and dental pain in 5- to 12-year-old children in Recife, Brazil. Eur Arch Paediatr Dent 2013; 14(1):15-9. https://doi.org/10.1007/s40368-012-0001-8

[9] Soares FC, Lima RA, de Barros MVG, Dahllöf G, Colares V. Development of dental anxiety in schoolchildren: A 2year prospective study. Community Dent Oral Epidemiol 2017; 45(3):281-8. https://doi.org/10.1111/cdoe.12290

[10] Boka V, Arapostathis K, Kotsanos N, Karagiannis V, van Loveren C, Veerkamp J. Relationship between child and parental dental anxiety with child's psychological functioning and behavior during the administration of local anesthesia. J Clin Pediatr Dent 2016; 40(6):431-7.

[11] Frankl S, Shiere F, Fogels H. Should the parent remain with the child in the dental operatory. J Dent Child 1962; 29:150-63.

[12] Boeira GF, Correa MB, Peres KG, Peres MA, Santos I, Matijasevich A, et al. Caries is the main cause for dental pain in childhood: findings from a birth cohort. Caries Res 2012; 46(5):488-95. https://doi.org/10.1159/000339491

[13] Neverlien PO. Assessment of a single-item dental anxiety question. Acta Odontol Scand 1990; 48(6):365-9.

[14] Ghaderi F, Fijan S, Hamedani S. How do children behave regarding their birth order in dental setting? Dent Shiraz Univ Med Sci 2015; 16(4):329-34.

[15] Aminabadi NA, Sohrabi A, Erfanparast LK, Oskouei SG, Ajami BA. Can birth order affect temperament, anxiety and behavior in 5 to 7-year-old children in the dental setting? J Contemp Dent Pract 2011; 12(4):225-31.

[16] Mendoza-Mendoza A, Perea MB, Yañez-Vico RM, Iglesias-Linares A. Dental fear in children: the role of previous negative dental experiences. Clin Oral Investig 2015; 19(3):745-51. https://doi.org/10.1007/s00784-014-1380-5

[17] Staugaard SR, Jøssing M, Krohn C. The role of negative and positive memories in fear of dental treatment. J Public Health Dent 2017; 77(1):39-46. https://doi.org/10.1111/jphd.12169 